\title{
Research on the Unethical Conducts and Practices among Professionals in the Construction Industry
}

\author{
Zulkifli Ibrahim, Noraini Hamzah, Muhamad Azry Khoiry
}

\begin{abstract}
Construction industry involved with large number of stakeholders. This industry has a complex contractual structure besides facing with several of psychological human behavior that exposed to the unethical conducts and practices among professionals. Professional ethics warmly has been discussed today within the construction industry. Ethics can be known as a major catalyst for the construction industry to attain status to a successful industry in the worldwide. As a result the aims to be a developed country can be achieved with cooperation from every structural in the construction community. However, without any changes on the unethical conducts and practices among professionals in the construction industry can make it all this becomes useless. Thus, the solid understandings and changes need to be executed, implemented and reinforced to ensure that the problems in the professional ethics can be resolved. This paper discusses and reviews on the unethical conducts and practices among professionals in the different countries such as Malaysia, Pakistan, Australia, Kenya, United Kingdom and China whereby the different behavior will be visible. The most common highlighted for the unethical conducts and practices among professionals in the construction industry were the corruption, negligence, unfair conduct, overriding on audit process over contracting process, favoritism, strict rule, conflict of interest, collusive tendering and violation of environmental ethics. In the previous studies, there were mechanism suggested whereby they are divided into three mechanisms included short, medium and long term solutions based on the project factors which are time, cost and quality. The mechanisms suggested can be catalyst in achieving and enhancing ethical conducts and practices among the professional in the construction industry. This review will provide useful information to every stakeholder in confronting with the unethical conducts and practices among professionals in the construction industry involved.

Index Terms - Construction industry, ethics, ethical issues, mechanisms, professional ethics
\end{abstract}

\section{INTRODUCTION}

The construction industry became an important part in the development and economic growth of each country in the world as it is a main component behind all activities related to development of infrastructures [1]. Basically, the construction industry was categorized into two classifications which are general construction and special trade [2]. General construction are divided into three categories namely civil engineering, residential and non-

Revised Manuscript Received on July 10, 2019.

Zulkifli Ibrahim, Civil and Structural Engineering Programme, Faculty of Engineering \& Built Environment, Universiti Kebangsaan Malaysia, 43650 Bangi, Malaysia. (zulkifli120988@siswa.ukm.edu.my)

Noraini Hamzah, Smart and Sustainable Township Research Centre, Faculty of Engineering \& Built Environment, Universiti Kebangsaan Malaysia, 43650 Bangi, Malaysia. (ainhamzah@ukm.edu.my)

Muhamad Azry Khoiry, Smart and Sustainable Township Research Centre, Faculty of Engineering \& Built Environment, Universiti Kebangsaan Malaysia, 43650 Bangi, Malaysia. (azrykhoiry@ukm.edu.my)

residential construction. For special trade involves with activities such as electrical work, plumbing, refrigeration and air conditioning, tiling, flooring and carpentry.

Reference [3] stated that construction process involves with the five main processes which are conceptualizing, designing, managing, organizing and coordination project requirements. This process involves with time, cost, technology, resources and methods. According to the Rules of Apexes, the achievement of quality, cost and time in the management of project in construction industry determines the success of a project. In order to achieve it, this industry need and demand from professional involves with engineers that hold the strong fundamental knowledge of engineering design and management principles besides knowledge of business procedure, human behavior and economics [3].

A significant increase in professionalism involves with construction industry over the years has led to increased cases of professional misconduct among professionals. Unethical conducts and practices among professionals have become anxious and deliberate discussion among the general public from day to day. This is due to exposure in mass media about misconduct and negligence among professionals from time to time [4]. With this exposure directly causes the community to become aware especially on the unethical conducts and practices among professionals. As a result, general public will do their job with taking an appropriate action towards the individual or group involved.

Although the value of worldwide construction industry is increasing but the industry still faces problems especially the unethical conducts and practices among professionals. But if the unethical conducts and practices among professionals cannot be resolved, this goal is difficult to achieve, practice and apply. The frequency of unethical conducts and practices among professional leading to the knock-on effect is high towards the construction industry [5]. Thus, these kinds of problem need to be solved with a properly and wisely in other to attain status as a develop country in the worldwide.

\section{METHODOLOGY}

The paper from previous studies was used for this review paper. There are 24 journals, 5 books and 3 organization's publisher were reviewed via in depth studies. The authors from Malaysia, Pakistan, Australia, Kenya, United Kingdom, China and India chosen to be reviewed. Thus, the

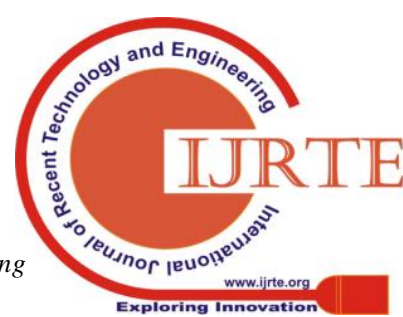




\section{RESEARCH ON THE UNETHICAL CONDUCTS AND PRACTICES AMONG PROFESSIONALS IN THE CONSTRUCTION INDUSTRY}

idea of unethical conducts and practices among professionals from previous studies were identified and listed randomly. Literature review used to familiarize with the topic and identified the unethical practices conducts and practices among professionals in construction industry.

\section{UNETHICAL CONDUCTS AND PRACTICES AMONG PROFESSIONALS IN CONSTRUCTION INDUSTRY \& RESULTS}

\section{A. Ethics}

Ethics can be defined in different perception but most of us understand that ethics involves with the moral values. Based on the construction industry view, ethical conducts and practices can be calculated and determined by the degree of integrity and trustworthiness of individuals and the companies in doing their business [4]. Thus there are a lot of ethics meaning and it look into the point of view and where it should be use. Ethics can be associated with moral in term of the philosophy related to human moral behavior [6]. Based on the Cambridge Advanced Learner's Dictionary 2008, it defines ethics was related to the study of what is morally right or wrong.

Besides that, ethics can be defines as the moral principles that empower someone from unethical conducts and practices within their particular profession [7]. In [8], the concept of morals was ability to be either right or wrong, good or bad, acceptable and unacceptable. Reference [9] provides four definitions of ethics which are (i) the discipline related with good and bad about moral duty and responsibility, (ii) a set of moral principles and values that was accepted of what supposed to be, (iii) a theory of moral principles that controls the behavior that is appropriate for individual group, (iv) a code of ethics.

Truly or good ethics is not all about definition because it does not set the Code of Ethics or specifies how the Code of Ethics might be provided in our daily work [10]. Referring to the literature stated that ethics does not simply identify good objective but also includes with making feasible choice or identifying the right or wrong choices [10], [11], [12]. We also can said ethics as helping others not only to be ethical but also to make wise decision in order to give benefit not only to own self but to the related organizations [13]. Ethics should not be isolated and separated from religion because it was considered and related to religion where every offence represented an act against the name of God [3]-[14].

In the Islamic context, terms such as justice, rightness, right, truth, kindness and taqwa have been described as 'salihat' while indecent acts are described as 'sayyi'at' or evil [6]. From the previous study, there are five basic consumptions which support the understanding and knowledge of ethics [10]-[15]. The consumptions are (i) process of professional ethics, (ii) human behavior is caused, (iii) actions have consequences and outcomes, (iv) ethical definition depends on the individual views, (v) good ethical business practice rely on mutual vulnerability.
Ethics also can be said as any moral values that we practices in our daily life. The choices on the right or wrong are all depends on us. Good ethics will lead into the right choices and vice versa.

\section{B. Profession and Professionals}

Profession can be synonymous with work. Basically, professional comprises of those involved in a certain profession such as medical, legislation, engineering, accounting and auditing, architecture and computing. In other words, being a professional in a certain profession means that the person considers his profession as a source of fixed income [16]. The profession is a work that requires both advanced study and mastering of a specialized body of knowledge and is implemented to promote, secure or protect some of the matter affecting and endangering the well-being of others [17]-[18].

Based on [17], the profession and professionals only can be used if it fulfills all this criteria which are (i) deep knowledge in the specific field, (ii) intensive and continuous training, (iii) essential services for the community, (iv) observance of a code of conduct, (v) autonomy, (vi) valid certification. Reference [19] stated that the professionals are expected to behave and act with honesty, fairness and integrity for every of their daily work routine. Based on [18], professional ethical awareness is influenced by several factors such as the stage of moral development, individual character, organizational and cultural structure as well as critical crisis issues especially in the construction industry.

Therefore, professional ethics is the norm system to handle both morality and professional's behaviour in their daily practice and reflect moral responsibility not only for individual but also others professionals practicing in every particular profession [20]. Becoming a professional must have extensive knowledge in specialized fields of endeavor so that unethical practices among professionals can be avoided in order to ensure project construction processes going smoothly.

\section{Professional Ethics}

The professional ethics definitions recognized by the the professional workers are to deliver and perform the best work to ensure that the interests of the customer can be safeguarded and attained appropriately but at the same time the wider public interest is also recognize and respect [13]. As a client of course they want to get the best services given from their respective nominated contractor thus relational and ethical issues should be discussed in order to solve the problem of unethical conducts and practices among professionals. Reference [17] said that professional ethics treats others with the same level of honesty and on how they would like to be treated by others.

The profession should have a high oversight to carry out their professional affairs without the influence of others professions [21]. Besides that, reference [22] stated that the professional ethics can be distinguished from general ethics to the extent that the professional ethics must be taken into account on (i) relationship between practicing professionals and customers or clients, (ii) relationship between the profession and society in 
general, (iii) relationship among professionals, (iv) relationship between employee and employer, and perhaps most importantly, (iv) particularize technical details of the profession.

\section{E. Code of Ethic}

In [1], construction professionals build and exercise their own skills and consideration whereby they are responsible to the customer and are bound by their professional code of ethics. Reference [18] defined the code of ethics as an official guide used by the organization or body to guide its members or professionals in ethical decisions and carry out their work ethically [18].

The different author said that the Code of Ethics is developed primarily for practical and professional use, adding to the building codes and other legal acts [23]. Based on author from reference [24] said that almost every profession has the Code of Ethics with providing the framework to achieve good ethical choices in their particular profession.

Reference [25] stated that some of the fundamental principles that support and approach engineers through the integrity, honor and dignity of the engineering profession as stated in the code of ethics include (i) enhancement of human and environment welfare using their knowledge and skill, (ii) being honest and fair to serve the loyalty to the public, employers and customers or clients, (iii) make great efforts to achieve and improve the proficiency and reputation of the engineering profession, (iv) reinforce and support the professional and technical community of their disciplines.

This Code of Ethics was conducted compliance with the ethical principles. Reference [26] stated that ethical conducts and practices is the adherence to the following ethical principles which are:

i Honesty - acting with honesty and avoiding conduct which may result in the fraud of another person directly or indirectly.

ii Fairness - not seeking profit that arises directly or indirectly from unfair service and treatment of others.

iii. Fair reward - avoid acts that may result in other being deprived of a fair reward for their work.

iv. Reliability - maintains the latest skills and provides services only in the competency area.

v. Integrity - taking into account the interests of the public, especially those who will use or gain interest in future project.

vi.Objectivity - identifies any potential conflicts of interest and discloses the conflict to any person affected by it.

vii.Accountability - provide information and warning on the matters within your knowledge that potentially harm others who may be affected by them. Warning must be given within sufficient time to enable effective action to be taken to avoid losses.

While each country has its own Code of Ethics, there are still unethical conducts and practices occur among professionals in construction industry. Thus the issues cannot be solved as simple as that.

\section{E. Unethical Conducts and Practices}

Unethical conducts and practices can occur at every phase of construction project which are planning and design, pre- qualification and tender, project implementation, operation and maintenance phase [2]. Based on reference [23], all this phases involve with process of conceptualizing, designing, managing, organizing and coordinating project requirements where the unethical conducts and practices will take place because it involves with time, money, resources, technology and methods.

This factor requires in order completing the construction project within the time, cost, quality and performance stated by the client. The unethical conducts and practices among professionals in construction industry from different country will be discussed further.

Table 1 is shown the previous research related to the unethical conducts and practices among professional in construction industry. The reader will be easily understood the unethical conducts and practices among professionals in different countries that happened in their construction industry.

Table 1. The previous research related to the unethical conducts and practices among professionals in construction industry

\begin{tabular}{|c|c|c|c|c|c|c|}
\hline & 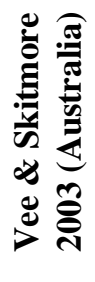 & 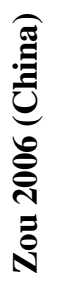 & 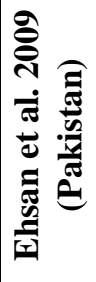 & 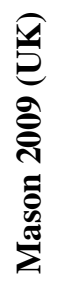 & 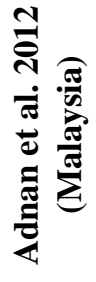 & 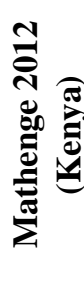 \\
\hline Corruption & $\checkmark$ & $\checkmark$ & $\checkmark$ & $\checkmark$ & $\checkmark$ & $\checkmark$ \\
\hline Negligence & $\checkmark$ & & & & $\checkmark$ & \\
\hline Unfair conduct & $\checkmark$ & & $\checkmark$ & & $\checkmark$ & $\checkmark$ \\
\hline $\begin{array}{l}\text { Overriding of } \\
\text { audit process } \\
\text { over contracting } \\
\text { process }\end{array}$ & & & $\checkmark$ & & & $\checkmark$ \\
\hline Favoritism & & & $\checkmark$ & & & $\checkmark$ \\
\hline Strict rule & & & $\checkmark$ & & & $\checkmark$ \\
\hline $\begin{array}{l}\text { Collusive } \\
\text { tendering }\end{array}$ & $\checkmark$ & & & & & \\
\hline $\begin{array}{l}\text { Conflict of } \\
\text { interest }\end{array}$ & $\checkmark$ & & & & & \\
\hline $\begin{array}{l}\text { Violation of } \\
\text { environmental } \\
\text { ethics }\end{array}$ & $\checkmark$ & & & & & \\
\hline
\end{tabular}

\section{i Corruption}

Corruption will be existed in many ways in the construction industry. Corruption can be classified in the forms of fraud, bribery, extortion and embezzlement in which these concepts are partly overlapping and at a time that can be exchanged with others concepts [2]. Referring to the literature, the terms corruption can be seen in form of bribery where it is involved with cash inducement, gift, favors, trips and appointment while respondents affirmed fraud involve stealing materials and non-logical demand for time extensions in the construction industry [2].

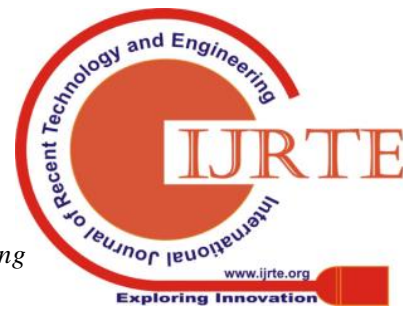




\section{RESEARCH ON THE UNETHICAL CONDUCTS AND PRACTICES AMONG PROFESSIONALS IN THE CONSTRUCTION INDUSTRY}

In [11]-[13], corruption also occurred in the construction industry among their professional.

/The corruption occur in the terms of bribery such as cash inducement, gifts and favors, entertainment, work for private homes, extra work from customers or clients and free trip either local or abroad [17]. Besides that, the authors also highlighted on the corruption in terms of fraud where it is the fraudulent conducts and practice in the construction industry of their country. Reference [17] wrote that the main examples of deliberate fraud include poor work performance and quality of the material quality during the inspections. Some of them were constructed with materials that does included in their quotation and deliberately over ordering of construction materials. Altering of construction documents and tampering during signed of contract document were the major examples of fraud in construction industry [17].

In [23], corruption occurred in term of bribery where it is directed straight by several professional establishments and business group around the world. Reference [25] wrote the unethical conducts and practices among professionals in their construction industry happened and occurred in the forms of bribery. The corruption arises in the industrial construction in two groups relating to contractors and professional officers of government officials consultant [27]. Furthermore, the corruption related to contractors includes offering bribes to obtain and win the project, deliberately lowering tender prices, and submitting false reports of project expenses. Referred to the author, the corruption associated with consultants, customers or clients and government officers comprised the administrative intervention, illegally awarded of project contract, disclosure of project baseline price and requested money from contractors [27].

The majority of contractors involved in corrupt practices mentioned they don't want to involve with this attitude but because they feel they are forced by the way the industry and the political environment operate and act to them [28][29].

\section{ii Negligence}

The negligence always happened in construction industry. Most of respondents had witnessed or experienced negligence in the construction industry that comprises of poor documents quality control, poor quality of work, poor quality of material and insufficient safety standards at the site project [2]. Besides that, some of the respondent reported inadequate information flow from clients or consultants to contractors and insufficient construction techniques was the forms of negligence [2].

Reference [17] wrote that most of respondents had experienced of negligence such as bad workmanship, poor material quality and insufficient safety standard practices in the construction industry of their country. The negligence mostly happened during project implementation phase as this conducts depends on the resources used in the project and on how the project was planned and managed.

\section{iii Unfair Conduct}

Unfair conduct can be seeing in the terms of dishonesty and unfairness. This unethical conducts and practices occur in the four main areas which are tender, bureaucracy or government policy, consultant fees, project costs, design and construction of contract agreements [2]. Some of them often exaggerate their capacity and qualifications to get jobs or projects and cheat their experience, capabilities and qualifications during the tender stage.

Referring to the literature, dishonesty and unfairness were the forms of unfair conduct mostly in tendering and implementation process in construction industry. The tendering practices assume that unfair conduct by both clients and the government mainly involves with biased tender evaluation systems, re-tender and bidding prices after tenders has been closed [17].

In [26], the unfair conduct in the type of cover pricing occurred among the professional in the construction industry. Furthermore, the unfair conducts was one of the most unethical conducts and practices among their professional in which undertakings work beyond their ability and capability [23]. Bid shopping also one of the forms of unfair conduct where the contractor exposes the offer price of one subcontractor to another in order to get a lower bid price [30].

The payment and project costs issue also have been highlighted by many of respondents. In addition, the respondents also stated that the client and developers did not pay on the consultant fees after engaging consultants will cause the project's cost discrepancies by the contractor consequently result and initiate dishonest and unfair conducts and practices.

\section{iv Overriding of Audit Process over Contracting Process}

The results was emphasized that audit staff dealing and involves with the construction industry should be not only focus on the financial but also focus on the most important part like technical competency [23]. In [25], this unethical conducts and practices also appeared among their professional with highest percentage.

\section{v Favoritism}

Favoritism was one of the major unethical conducts and practices among the professional in the construction industry [23]. In [25], favoritism also happened in their construction industry where the percentage is quite high. Thus, it shown that this an unethical practices always happened in the construction field.

\section{vi Strict Rule}

Reference [23] state that strict rule had less percentage on the unethical conducts and practices among professionals in their country. Reference [25] mentioned that this kind of conducts and practices happened in the construction industry but does not had a high percentage compared to the others unethical conducts and practices.

\section{vii Collusive Tendering}

Most of respondents witnessed and experienced on collusive tendering in the tendering phase in the construction industry [17]. In the construction industry, the collusive tendering experienced in the form of coverpricing, hidden fees, bid-cutting, commission and tender cost compensation [17].

In [26], the unethical conducts and practices among professionals during the

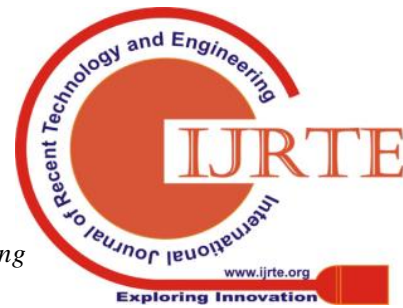


tender process are reverse auctions where open tender procedures were used and the tendered winner was provided the lowest price when decision was set. Some of them see the reverse auctions as important and valuable in the procurement process but most of contractors disagree and describe this as unethical conducts and practices.

\section{viii Conflict of interest}

In [17] stated that the conflict of interest include the consultant using their position for financial gain from contractor. Besides that, some of clients awarded the contracts to the companies in which they have an interest and benefit with them. The role of government is to deliver services. However, under current situation is quite different whereby the public sector needs to compete with the private sector through their related business and developed project.

Therefore, conflict of interests arises in this situation. Reference [17] also stated that the granting of contracts to the ex-employees and companions cause the conflict of interest besides maintaining impartially when representing clients. Each of level needs to cooperate between each other's to prevent from the conflict to appear during project execution.

\section{xi Violation of Environmental Ethics}

In the course of this unethical conducts and practices, builders fail to stop erosion and environmental issues in the construction industry [17]. In addition, there are some issues regarding cleaning of unsolicited plant and building debris where the builder fails to do so due this unethical conducts and practices. This conducts will affect human health too if there is no control and prevention from this activity. Thus, every party needs to look at ways to resolve the problem.

\section{F. Mechanism on the Prevention of Unethical Conducts and Practices}

Although the unethical conducts and practices among professionals in construction industry continuously happened, we need to have some mechanisms to avoid and prevent this problem spreading widely in our society today.

Thus, previous studied divided the mechanism on prevention into three measured which were short, medium and long term measures.

\section{Short Term Measures}

Referring to the literature, the penalties, corrective measures, or cancellation of licenses for repeated infringement should be introduced [2]-[23]. The organization such as anti-corruption commission should involve on this matters. Reference [2] wrote that the introduction of the integrity pact was imperative as a tool for clean bidding during tendering process. Besides that, each of organization should lead ethical practices through organizational leadership. It is a top management moral obligation to set personal examples in the demonstrating ethical conduct in the company or workplace where full support must be given towards the enforcement of the Code of Ethics throughout the board or organizations [5].

Furthermore, the institutions of regular and random checks should be created. It is important to review and checking on the professional involved in the construction industry through regular and random checks [27]. Reference
[27] wrote that the supervisory officers should be given roles and responsibilities in respect of the implementation of public officials involved in the construction industry. Thus, the supervision and observation on the process and work during the project life cycle need to give priority as it is one of the mechanisms used to prevent the unethical conducts and practices among professionals in construction industry.

In [31], the implementing of ethical management systems in some organizations need the support from organizational culture as it was formulated at the senior management while power structure was implemented by the senior management. Therefore, the ethical conducts and practices always starts at the top level as a role model. The Code of Ethics implementation in a country can make it as a guideline in practicing ethical conducts and practices in their respective professional professions in the construction industry [32].

\section{ii Medium Term Measures}

In order to ensure quality along with ethical practices among professionals in the construction industry, the native quality assurance group should be forming at each of project team [2]-[23]. Besides that, the training with qualified organizations should be regulated and mandatory for new technical graduates where it takes times about six months to manage and expose them on professional matters including aspects of ethics especially in construction field [2]-[23].

Reference [32] also wrote that ethical training programs should be held and conduct where adequate funds should be allocated for the training and it can support for all employees within organizations or companies to attend for the training. Reference [2] and [23] mentioned that the role of the media in contributing and promoting the ethical society is more relevant today to address the problem of ethical dilemma and ethical society formation by debating these issues openly.

\section{iii Long Term Mesaures}

The function of the independent judiciary in implementing the law should be emphasized by our government. Referring to literature review, the specific laws should be drafted by the government to check the unethical practices by hiring an official organization [2]-[23]. This organization appointed to investigate individuals or group complaints against unethical conducts and practices among professionals [2]-[23]. Refer to [2]-[23], the research and development should be undertaken in both public and private sectors in order to effectively address on the ethical issues besides the technical manpower only allowed to work until they are properly trained through recognized training institutions.

Besides that, empowering ethical education is considered essential to establish a professional foundations along with input on its roles in the industry from professional institutions to his professional life where its can be as a check and balance ethics structure.The Code of Ethics for entire industry is considered necessary to encourage and promote overall ethical environment especially in the construction industry [2]. Reference [23] wrote that civic bodies should be led by

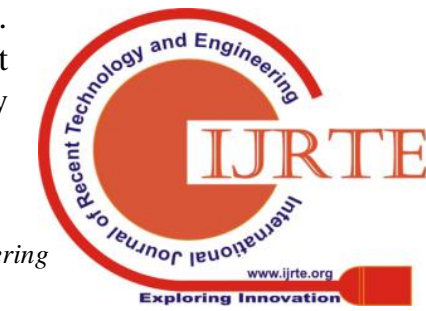




\section{RESEARCH ON THE UNETHICAL CONDUCTS AND PRACTICES AMONG PROFESSIONALS IN THE CONSTRUCTION INDUSTRY}

people who have adequate ethical training because they will be more responsible in ensuring ethical practices in the institutions as well as environment surrounding them are practiced.

The development of an honest and ethical construction culture at both corporate and industry levels are one of the mechanism in prevention of unethical conducts and practices among professionals. In addition, the government should strive in promoting honest and healthy rights all the time in form of technically, morally, ethically and culturally [27].

\section{CONCLUSION}

The construction industry plays an important part in the economic growth by contribution toward the development of country in worldwide. The unethical conducts and practices among professionals work in the construction industry often happen without knowing and realizing it. In this paper the unethical conducts and practices among professionals in the construction industry were reviewed. The mechanism of prevention from unethical conducts and practices also be discussed and reviewed in this paper.

This review will provide useful information to every stakeholder in confronting with the unethical conducts and practices among professionals in the construction industry involved. In future studies, this review paper will be focus via in-depth study. The study will build a model of professionals in construction in order to prevent and eliminate the problem in a new era.

\section{ACKNOWLEDGEMENT}

This research supported by Universiti Kebangsaan Malaysia using research funds grants scheme GGPM-2017058. We would like to thank our colleagues from Universiti Kebangsaan Malaysia (UKM), who provided insight and expertise in this research.

\section{REFERENCES}

1. S. Toor and G. Ofori, "Leadership for future construction Journal of Project Management 26(6), pp. 620-630, 2008.

2. H. Adnan, N. Hashim, N.M. Yusuwan and N. Ahmad, N. "Ethical issue in the construction industry: contractor's perspective," Procedia- Social and Behavioral Sciences 35, pp. 719-727, 2012.

3. M. Lewis, "Islam and accounting," Accounting Forum, 25(2), pp. 103-127, 2001.

4. J. Mason, "Promoting ethical improvement in the construction industry: A single professional code," Proceedings from the Construction and Building Research Conference of the Royal Institute of Chartered Surveyors Dublin Institute of Technology. 4-5th September, London, pp. 1-12, 2008.

5. F. M. Arain, "Causes of insolvency and unethical practices of contractors in Pakistan construction industry," Building resilience, International Conference on Building Education and Research (BEAR), pp. 1246-1260, 2008.

6. S. A. Abuznaid, "Business ethics in Islam: The glaring gap in practice," International Journal of Islamic and Middle Eastern Finance and Management 2(4), pp. 278-288, 2009.

7. C. Soanes and S. Hawker, "Compact Oxford English Dictionary of Current English," 3rd Edition, The University of California: Oxford University Press, 2008. minimizing unethical conducts and practices among industry: Agenda for authentic leadership," International

8. M. G. Velasquez, "Business ethics: Concepts and cases," Prentice-Hall: New York, 2009.

9. FMI/CMAA, "Survey of construction industry ethical practices and issues," Management Consultant for The Construction Industry and Construction Management Association of America, pp.1-18, 2004.

10. L. O. Oyewobi, B.O.Ganiyu, A. A. Oke, A. W. OLA-AWO and A. A. Shittu, "Determinants of unethical performance in Nigerian construction industry," Journal of Sustainable Development 4(4), 2011.

11. P. Bowen, A. Akintoye, R. Pearl and P. J. Edwards, "Ethical behaviour in the South African construction industry, "Construction Management and Economics, pp. 631-648, 2007.

12. R. Pearl, P. Bowen, N. Makanjee, A. Akintoye and K. Evans, "Professional ethics in the South African construction industry - A pilot study," Journal of Construction Management and Economics 25, Issues 6, pp. 631-648, 2007.

13. O. C. Ferrell and J. Fraedrich, "Business ethics: Ethical decision making \& cases, "Cengage learning, 2014.

14. N. Mohamad, I. M. S. Usman, N. Mohamad, M. Surat, "Significance of ethics education and training for construction professionals," Significance of Ethics Education and Training for Construction Professionals, 7, 2014.

15. RICS, "Professional ethics guidance note: Part 1 Introduction," RICS Professional Regulation and Consumer Protection Department, London, 2000.

16. M. J. Johari, "Etika profesional," Penerbit Universiti Teknologi Malaysia, pp. 3-7, 2001

17. C. Vee and R. M. Skitmore, "Professional ethics in the construction industry," Engineering Construction and Architectural Management 10 (2): pp. 117-127, 2003.

18. H. A. Rahman, C. Wang, N. Mohamad and M. Ebrahimi, "Professional ethics in the construction industry," University of Malaya: University of Malaya Press, pp. 3-6, 2016.

19. R. Pearl, P. Bowen, N. Makanjee, A. Akintoye and K. Evans, "Professional ethics in The South African construction industry - A pilot study," In: Sidwell, A. C., (ed.), The Queensland University of Technology Research Week International Conference, Brisbane, Australia, 4-8th July 2005, pp. 1-6, 2005.

20. H. Corvellec and N. Macheridis, "The moral responsibility of project selectors," International Journal of Project Management 28(3), pp. 212-219, 2010.

21. J. Ogachi, "The Status of the procurement profession in Kenya: Baseline indicators, "Journal of the Association of Professional Societies in East Africa, 3, pp. 1-34, 2011.

22. S. Sinha, T. Randolph and J. Kulka, "Integrating Ethics Into Engineering Design of Construction Process," American Society For Engineering Education Annual Conference \& Exposition, 2004.

23. N. Ehsan, S. Anwar and M. Talha, M. 2009, "Professional ethics in construction industry of Pakistan," Proceeding of the World Congress on Engineering 2009, 1, London, U.K, 2009.

24. H. A. Rahman, C. Wang and X. W. Yap, "How professional ethics impact construction quality: Perception and evidence in a fast developing economy," Scientific Research and Essays 52(23), pp. 3742-3749, 2010.

25. G.D.Mathenge, "Ethical issues in the construction industry in Kenya: A critical analysis of the professional conduct in Engineering Technology Management," Industrial Engineering Letters, 2(7), 2012.

26. J. Mason, "Ethics in the Construction Industry: The Prospects for A Single Professional Code," International Journal of

Law

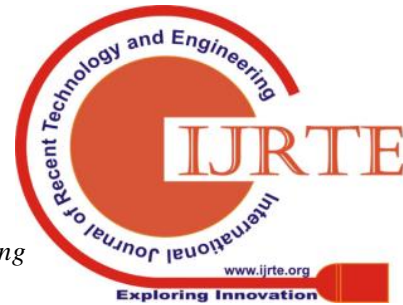


in the Built Environment, 1(3), pp. 194-205, 2009.

27. P. X. W. Zou, "Strategies for minimizing corruption in the construction industry in China," Journal of Construction in Developing Countries, 11(2), pp. 15-29, 2006.

28. N. Stansbury, "Exposing the foundations of corruption construction," United Kingdom: Transparency International, 2005.

29. R. M. Nordin, R. Takim and A. H. Nawawi, "Behavioural factors of corruption in the construction industry, "Procedia Social and Behavioral Sciences 105, pp. 64-74, 2013.

30. E. Degn and K. R. Miller, "Journal of Construction Education 8(1), pp. $47-55,2003$.

31. H. Suen, S. Cheung and R. Mondejar, "Managing ethical behaviour in construction organizations in Asia: How do the teachings of Confucianism, Taoism and Buddhism and globalization influence ethics management? "International Journal of Project Management 25, pp. 257-265, 2007.

32. T. Nawaz and A. A. Ikram, N. Hashim, "Unethical practices in Pakistani construction industry," European Journal of Business and Management, 5(4), pp. 188-203, 2013. 